\title{
Effects of Lu and Tm Doping on Thermoelectric Properties of $\mathrm{Bi}_{2} \mathrm{Te}_{3}$ Compound
}

\author{
MAXIM YAPRINTSEV ${ }^{1}$ ROMAN LYUBUSHKIN,${ }^{1}$ OXANA SOKLAKOVA, ${ }^{1}$ \\ and OLEG IVANOV (D) ${ }^{1,2,3}$
}

1.-Belgorod State University, Belgorod, Russian Federation 394015. 2.-Voronezh State Technical University, Voronezh, Russian Federation 394026. 3.—e-mail: Ivanov.Oleg@bsu.edu.ru

\begin{abstract}
The $\mathrm{Bi}_{2} \mathrm{Te}_{3}, \mathrm{Bi}_{1.9} \mathrm{Lu}_{0.1} \mathrm{Te}_{3}$ and $\mathrm{Bi}_{1.9} \mathrm{Tm}_{0.1} \mathrm{Te}_{3}$ thermoelectrics of $n$-type conductivity have been prepared by the microwave-solvothermal method and spark plasma sintering. These compounds behave as degenerate semiconductors from room temperature up to temperature $T_{\mathrm{d}} \approx 470 \mathrm{~K}$. Within this temperature range the temperature behavior of the specific electrical resistivity is due to the temperature changes of electron mobility determined by acoustic and optical phonon scattering. Above $T_{\mathrm{d}}$, an onset of intrinsic conductivity takes place when electrons and holes are present. At the Lu and Tm doping, the Seebeck coefficient increases, while the specific electrical resistivity and total thermal conductivity decrease within the temperature 290$630 \mathrm{~K}$ range. The increase of the electrical resistivity is related to the increase of electron concentration since the $\mathrm{Tm}$ and $\mathrm{Lu}$ atoms are donor centres in the $\mathrm{Bi}_{2} \mathrm{Te}_{3}$ lattice. The increase of the density-of-state effective mass for conduction band can be responsible for the increase of the Seebeck coefficient. The decrease of the total thermal conductivity in doped $\mathrm{Bi}_{2} \mathrm{Te}_{3}$ is attributed to point defects like the antisite defects and $\mathrm{Lu}$ or Tm atoms substituting for the $\mathrm{Bi}$ sites. In addition, reducing the electron thermal conductivity due to forming a narrow impurity ( $\mathrm{Lu}$ or $\mathrm{Tm}$ ) band having high and sharp density-ofstates near the Fermi level can effectively decrease the total thermal conductivity. The thermoelectric figure-of-merit is enhanced from $\sim 0.4$ for undoped $\mathrm{Bi}_{2} \mathrm{Te}_{3}$ up to $\sim 0.7$ for $\mathrm{Bi}_{1.9} \mathrm{Tm}_{0.1} \mathrm{Te}_{3}$ and $\sim 0.9$ for $\mathrm{Bi}_{1.9} \mathrm{Lu}_{0.1} \mathrm{Te}_{3}$.
\end{abstract}

Key words: $\mathrm{Bi}_{2} \mathrm{Te}_{3}$ compound, rare earth element doping, thermoelectric properties

\section{INTRODUCTION}

Currently, bismuth telluride, $\mathrm{Bi}_{2} \mathrm{Te}_{3}$ and $\mathrm{Bi}_{2} \mathrm{Te}_{3}$ based compounds are the best thermoelectric materials for applications around room temperature. ${ }^{1-3}$ Unfortunately, thermoelectric efficiency of these compounds defined by the thermoelectric figure-ofmerit, $Z T$, remained too low $(Z T \leq 1)$ until now. As is known, ${ }^{4}$ the dimensionless figure-of-merit is expressed as $\left(S^{2} / \rho k\right) T$, where $T$ is the absolute temperature, $S$ is the Seebeck coefficient, $\rho$ is the specific electrical resistivity, and $k$ is the total

(Received August 21, 2017; accepted November 7, 2017; published online November 20, 2017) thermal conductivity with contributions from crystal lattice and carriers. Therefore, lower $k$ and $\rho$, and higher $S$, should be combined for material to reach a higher $Z T$ value. A number of investigations using various physical and technological approaches have been carried out to improve the thermoelectric properties of $\mathrm{Bi}_{2} \mathrm{Te}_{3} \cdot{ }^{5-13} \mathrm{~A}$ doping is one of obvious and promising ways to optimally combine the $S, \rho$ and $k$ values and enhance $Z T$ of materials. ${ }^{14-16}$

Recently, it was found that rare earth element ( $\mathrm{Lu}, \mathrm{Ce}, \mathrm{Sm}, \mathrm{Er}, \mathrm{La}$, etc.) doping can be used to enhance the thermoelectric performance of $\mathrm{Bi}_{2} \mathrm{Te}_{3}{ }^{17-24}$ There are several effects of the rare earth element doping: (1) the increase of carrier concentration due to donor-like effects at rare earth 
elements substituting for $\mathrm{Bi}$ site in the $\mathrm{Bi}_{2} \mathrm{Te}_{3}$ lattice; (2) the increase of the electron and phonon scattering by point defects forming in the crystal lattice at the doping; (3) the increase of the Seebeck coefficient by enhanced electron states forming near the Fermi level; and (4) the additional increase of carriers scattering by localized magnetic moments of some rare earth elements.

The aim of this paper is to study effects of rare earth element doping on the thermoelectric properties of the $\mathrm{Bi}_{2} \mathrm{Te}_{3}$ compound. Lutetium, $\mathrm{Lu}$, and tullius, Tm, were used as dopants to prepare the $\mathrm{Bi}_{1.9} \mathrm{Lu}_{0.1} \mathrm{Te}_{3}$ and $\mathrm{Bi}_{1.9} \mathrm{Tm}_{0.1} \mathrm{Te}_{3}$ compositions.

\section{EXPERIMENTAL}

Microwave-solvothermal synthesis was applied to prepare the starting powders of the $\mathrm{Bi}_{2} \mathrm{Te}_{3}$, $\mathrm{Bi}_{1.9} \mathrm{Lu}_{0.1} \mathrm{Te}_{3}$ and $\mathrm{Bi}_{1.9} \mathrm{Tm}_{0.1} \mathrm{Te}_{3}$ compositions. As is known, compared with the conventional methods, the microwave-assisted heating technique has the advantages of very short time of synthesis, simplicity and energy efficiency, small particle size of the products and narrow particle size distribution, and high purity of powder. ${ }^{25,26}$

Analytically pure chemicals were used for the synthesis (bismuth oxide, $\mathrm{Bi}_{2} \mathrm{O}_{3}$, tellurium oxide, $\mathrm{TeO}_{2}$, lutetium oxide, $\mathrm{Lu}_{2} \mathrm{O}_{3}$, tullius oxide, $\mathrm{Tm}_{2} \mathrm{O}_{3}$, ethylene glycol, nitric acid and $N, N$ dimethylformamide).

The $\mathrm{Bi}_{2} \mathrm{O}_{3}, \mathrm{TeO}_{2}$ and $\mathrm{Lu}_{2} \mathrm{O}_{3}$ or $\mathrm{Tm}_{2} \mathrm{O}_{3}$ oxides taken in a stoichiometric ratio were dissolving in a mixture of concentrated nitric acid and ethylene glycol. Then, $N, N$-dimethylformamide was added in the mixture after dissolving. The microwave-assisted reaction was carried out in a MARS-6 microwave reactor with a power of $1000 \mathrm{~W}$ and at $2.45 \mathrm{MHz}$ working frequency. The synthesis was carried out for $15 \mathrm{~min}$ at temperature of $463 \mathrm{~K}$ and pressure of 40 bars.

The spark plasma sintering method, by using a SPS-25/10 system, was applied to sinter the bulk materials at a pressure of $40 \mathrm{MPa}$, a temperature of $683 \mathrm{~K}$ and a sintering time of $5 \mathrm{~min}$.

The densities of the bulk samples were measured by the Archimedes' method.

X-ray diffraction (XRD) analysis was performed by a Rigaku Ultima IV diffractometer with $\mathrm{Cu} K_{\alpha}$ radiation to determine the phase composition of the starting powders and the bulk materials.

To determine the correct elemental composition of materials prepared, a Shimadzu ICP (Inductively Coupled Plasma) emission spectrometer ICPE-9000 was applied.

A scanning electron microscope (SEM), a Nova NanoSEM 450, was used to study the microstructure features of the bulk samples. The energy dispersive x-ray spectroscopy (EBSD) method was applied to map the distribution of chemical elements for the bulk $\mathrm{Bi}_{2} \mathrm{Te}_{3}, \mathrm{Bi}_{1.9} \mathrm{Lu}_{0.1} \mathrm{Te}_{3}$ and $\mathrm{Bi}_{1.9} \mathrm{Tm}_{0.1} \mathrm{Te}_{3}$ compounds.
The specific electrical resistivity, $\rho$, and the Seebeck coefficient, $S$, were measured by using a ZEM-3 system.

To determine the type, concentration, $n$, and mobility, $\mu_{\mathrm{H}}$, of the majority charge carriers, the Hall effect was studied by a Cryogenic Free system.

A TC-1200 system was applied to determine the thermal conductivity, $k$, by the laser flash method. Measurement by the laser flash method finds thermal diffusivity based on the temperature change with time of the back side of a sample after heating the front side with laser beam instantaneously. The thermal conductivity of a sample is found from the thermal diffusivity $\alpha$, the specific heat $C_{\mathrm{p}}$ and the density $d$ using the $k=\alpha \cdot \mathrm{C}_{\mathrm{p}} \cdot d$ equation. For the measurement of the specific heat, a standard sample is used at room temperature to find the absorbed energy of the sample. Then the specific heat of an unknown sample is found at a target temperature by comparing the temperature changes of the sample at room temperature and target temperature, assuming that the same heat capacity is absorbed by the unknown sample.

\section{RESULTS AND DISCUSSION}

The XRD patterns for the bulk $\mathrm{Bi}_{2} \mathrm{Te}_{3}$, $\mathrm{Bi}_{1.9} \mathrm{Lu}_{0.1} \mathrm{Te}_{3}$ and $\mathrm{Bi}_{1.9} \mathrm{Tm}_{0.1} \mathrm{Te}_{3}$ compounds taken at room temperature are shown in Fig. 1. According to the XRD analysis, all sintered materials are of the single hexagonal phase characteristic for pure $\mathrm{Bi}_{2} \mathrm{Te}_{3}$. The $\mathrm{Lu}$ and $\mathrm{Tm}$ atoms are believed to incorporate to the $\mathrm{Bi}_{2} \mathrm{Te}_{3}$ lattice changing the lattice parameters. The lattice $a$ and $c$ parameters calculated by the Rietveld refinement are listed in Table I. In fact, the $a$ and $c$ changes are very small and close to accuracy of the XRD analysis. So, just the weak effect of the $\mathrm{Lu}$ and $\mathrm{Tm}$ doping on the $\mathrm{Bi}_{2} \mathrm{Te}_{3}$ structure could be found in XRD phases.

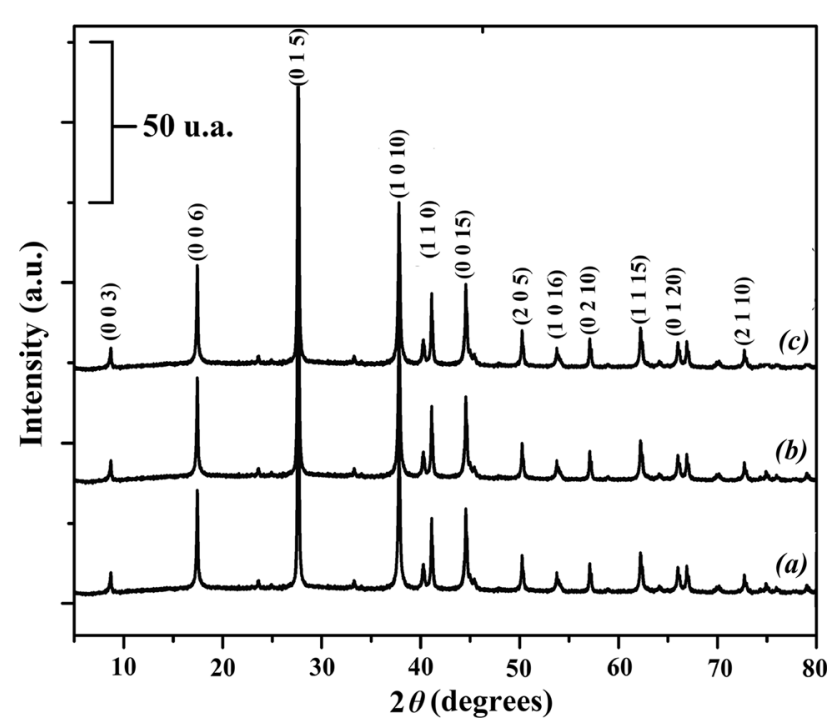

Fig. 1. XRD patterns of $\mathrm{Bi}_{2} \mathrm{Te}_{3}$ (a), $\mathrm{Bi}_{1.9} \mathrm{Lu}_{0.1} \mathrm{Te}_{3}$ (b) and $\mathrm{Bi}_{1.9} \mathrm{Tm}_{0.1} \mathrm{Te}_{3}$ (c). 
Table I. Lattice parameters and elemental compositions of $\mathrm{Bi}_{2} \mathrm{Te}_{3}, \mathrm{Bi}_{1.9} \mathrm{Lu}_{0.1} \mathrm{Te}_{3}$ and $\mathrm{Bi}_{1.9} \mathrm{Tm}_{0.1} \mathrm{Te}_{3}$

\begin{tabular}{|c|c|c|c|c|c|c|}
\hline Compound & $a(\AA)$ & $c(\AA)$ & Bi (at.\%) & Te (at.\%) & Lu (at.\%) & Tm (at.\%) \\
\hline $\mathrm{Bi}_{2} \mathrm{Te}_{3}$ & 4.385 & 30.476 & 40.00 & 60.00 & - & - \\
\hline $\mathrm{Bi}_{1.9} \mathrm{Tm}_{0.1} \mathrm{Te}_{3}$ & 4.387 & 30.484 & 38.04 & 60.00 & - & 1.96 \\
\hline $\mathrm{Bi}_{1.9} \mathrm{Lu}_{0.1} \mathrm{Te}_{3}$ & 4.388 & 30.481 & 38.03 & 60.00 & 1.98 & - \\
\hline
\end{tabular}

Weakness of this effect should be attributed to a small difference between ionic radii of $\mathrm{Lu}(1.001 \AA)$, tullius $(1.020 \AA)$ and bismuth $(1.100 \AA) .{ }^{27}$

The compositions of the compounds prepared were analyzed by the ICP emission spectrometer. As wastage and volatilization are unavoidable during spark plasma sintering, the real composition may deviate from the nominal one. However, according to analysis results, content of various elements really corresponds to the $\mathrm{Bi}_{2} \mathrm{Te}_{3}$, $\mathrm{Bi}_{1.9} \mathrm{Lu}_{0.1} \mathrm{Te}_{3}$ and $\mathrm{Bi}_{1.9} \mathrm{Tm}_{0.1} \mathrm{Te}_{3}$ compositions (Table I).

Clear crystalline grained structures with mean grain size of $\sim 1 \mu \mathrm{m}$ were observed by the SEM method for all the compositions. No remarkable changes in the grain structures were found for $\mathrm{Bi}_{2} \mathrm{Te}_{3}, \mathrm{Bi}_{1.9} \mathrm{Lu}_{0.1} \mathrm{Te}_{3}$ and $\mathrm{Bi}_{1.9} \mathrm{Tm}_{0.1} \mathrm{Te}_{3}$. The SEM images of the samples surfaces are shown in Fig. 2.

The densities of the bulk samples were equal to $6.72 \mathrm{~g} / \mathrm{cm}^{3}, 6.82 \mathrm{~g} / \mathrm{cm}^{3}$, and $6.75 \mathrm{~g} / \mathrm{cm}^{3}$ for $\mathrm{Bi}_{2} \mathrm{Te}_{3}$, $\mathrm{Bi}_{1.9} \mathrm{Lu}_{0.1} \mathrm{Te}_{3}$ and $\mathrm{Bi}_{1.9} \mathrm{Tm}_{0.1} \mathrm{Te}_{3}$, respectively, which are $87 \%, 88.5 \%$, and $88 \%$ of the theoretical density of $\mathrm{Bi}_{2} \mathrm{Te}_{3}\left(7.7 \mathrm{~g} / \mathrm{cm}^{3}\right)$. In fact, the densities of the samples under study are less than the theoretical density. However, it is important to note these densities are weakly dependent on the composition of compounds. The main purpose of this paper is to find the of the $\mathrm{Lu}$ and Tm doping on the thermoelectric properties of $\mathrm{Bi}_{2} \mathrm{Te}_{3}$. So, the densities of both undoped and doped $\mathrm{Bi}_{2} \mathrm{Te}_{3}$ should be the same to find this effect.

To confirm the uniformity of elements distribution, the EBSD method was applied. The results of EBSD for $\mathrm{Bi}_{1.9} \mathrm{Lu}_{0.1} \mathrm{Te}_{3}$ are presented in Fig. 3. One can see from the EBSD mapping that the chemical elements are uniformly distributed.

So, both phase compositions and grain structures of $\mathrm{Bi}_{2} \mathrm{Te}_{3}, \mathrm{Bi}_{1.9} \mathrm{Lu}_{0.1} \mathrm{Te}_{3}$ and $\mathrm{Bi}_{1.9} \mathrm{Tm}_{0.1} \mathrm{Te}$ are the same. Then, sufficient changes of the thermoelectric properties of these compounds discussed further should be attributed to the Lu and Tm doping effect.

According to the Hall effect study, the majority charge carriers for all the compounds are electrons. It is known ${ }^{28-30}$ that the type and carriers concentration in $\mathrm{Bi}_{2} \mathrm{Te}_{3}$ are closely related to point defects. The most common defects are antisite defects of $\mathrm{Bi}$ at the Te sites (negatively charged $\mathrm{Bi}_{\mathrm{Te}}^{\prime}$, accompanied with formation of one hole, $h$ ), vacancies at the $\mathrm{Te}$ sites (positively charged $\mathrm{V}_{\mathrm{Te}}^{*}$, providing two electrons, $e^{\prime}$, per defect), and vacancies at the $\mathrm{Bi}$ sites (negatively charged $\mathrm{V}_{\mathrm{Bi}}^{\prime \prime \prime}$, contributing three
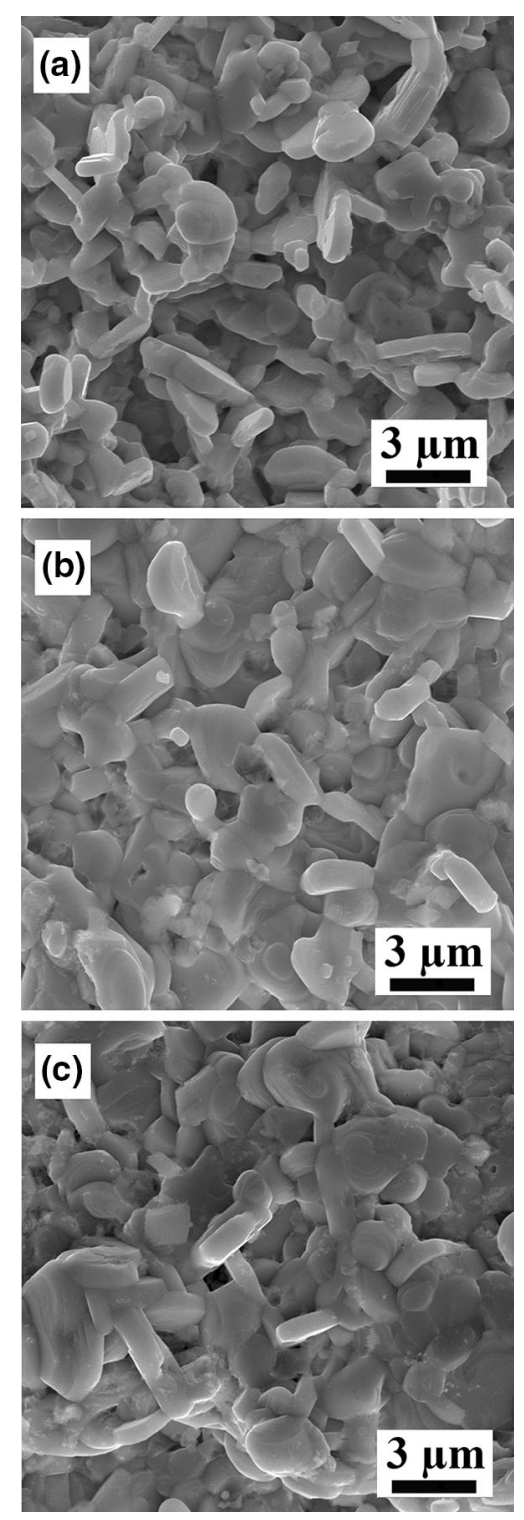

Fig. 2. SEM images on the $\mathrm{Bi}_{2} \mathrm{Te}_{3}$ (a), $\mathrm{Bi}_{1.9} \mathrm{Lu}_{0.1} \mathrm{Te}_{3}$ (b) and $\mathrm{Bi}_{1.9} \mathrm{Tm}_{0.1} \mathrm{Te}_{3}$ (c) surfaces.

holes per defect). Since the energy of evaporation for $\mathrm{Te}(52.55 \mathrm{~kJ} / \mathrm{mol})$ is much lower than that of $\mathrm{Bi}$ $(104.80 \mathrm{~kJ} / \mathrm{mol})$, the evaporation of $\mathrm{Te}$ is much easier than that of $\mathrm{Bi}$. Each $\mathrm{V}_{\mathrm{Te}}^{. \prime}$ vacancy leaves two free electrons, as described in Eq. 1 


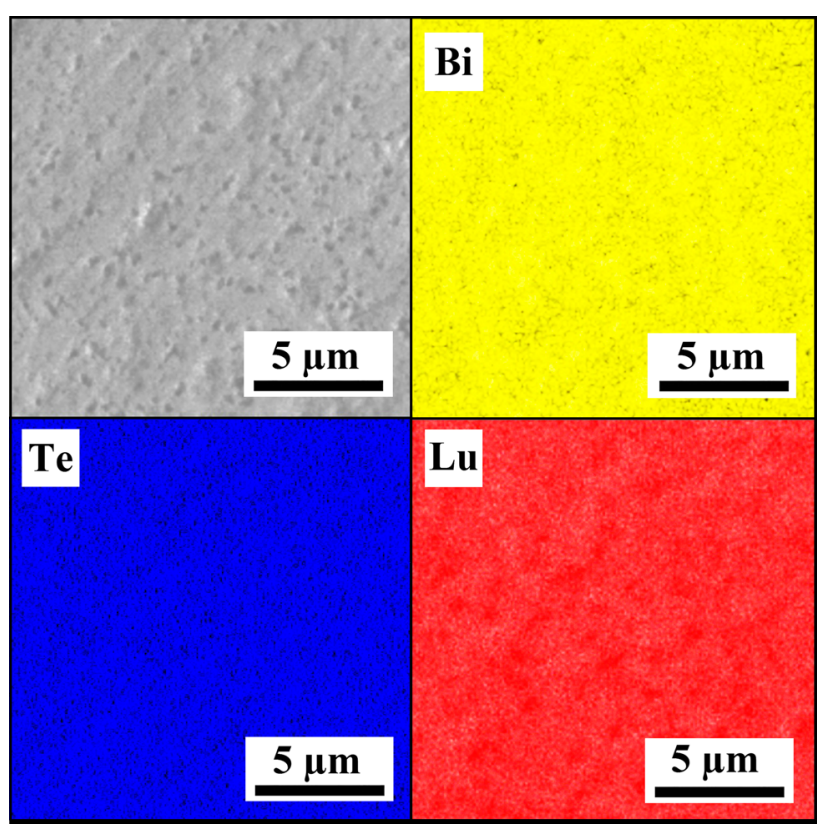

Fig. 3. EBSD mapping of chemical elements on the $\mathrm{Bi}_{1.9} \mathrm{Lu}_{0.1} \mathrm{Te}_{3}$ surface.

$$
\mathrm{Bi}_{2} \mathrm{Te}_{3}=2 \mathrm{Bi}_{\mathrm{Bi}}^{\times}+2 \mathrm{Te}_{\mathrm{Te}}^{\times}+\mathrm{Te}(g)+\mathrm{V}_{\mathrm{Te}}^{*}+2 e^{\prime},
$$

where symbol $g$ is corresponding to a gaseous phase.

The $\mathrm{V}_{\mathrm{Bi}}^{\prime \prime \prime}$ and $\mathrm{V}_{\mathrm{Te}}$ vacancies always have a ratio equal to $2: 3$, resulting in a zero net free charge, as shown in Eq. 2

$$
\begin{aligned}
5 \mathrm{Bi}_{2} \mathrm{Te}_{3}= & 8 \mathrm{Bi}_{\mathrm{Bi}}^{\times}+10 \mathrm{Te}_{\mathrm{Te}}^{\times}+5 \mathrm{Te}(g)+\left(2 \mathrm{~V}_{\mathrm{Bi}}^{\prime \prime \prime}+3 \mathrm{~V}_{\mathrm{Te}}^{\prime \prime}\right) \\
& +2 \mathrm{Bi}_{\mathrm{Te}}^{\prime}+2 h .
\end{aligned}
$$

Due to small differences in electronegativity between $\mathrm{Te}$ and $\mathrm{Bi}$, antisite defects are induced since $\mathrm{Bi}$ can easily jump from $\mathrm{Bi}$ site to $\mathrm{Te}$ site contributing one hole as a free carrier (Eq. 2).

For polycrystalline samples, the dangling bonds at grain boundaries due to Te deficiencies can be considered as fractional-working as $n$-type dopants in the same manner as the whole-defects inside the grains. This is the reason why the most polycrystalline $\mathrm{Bi}_{2} \mathrm{Te}_{3}$ samples are $n$-type semiconductors. Moreover, for the polycrystalline samples prepared by the deformation methods including the ball milling, hot pressing and spark plasma sintering, the deformation can induce a donor-like effect to take place. In these methods, the deformation can result in the non-basal slip and produce, on average, $3 \mathrm{Te}$ to $2 \mathrm{Bi}$ vacancy-interstitial pairs. ${ }^{29}$ When abundant $\mathrm{Bi}$ vacancies are created, the $\mathrm{Bi}$ atoms occupying the Te sites would more readily move back into its original sublattices and excess Te vacancies are produced as described in Eq. 3

$$
2 \mathrm{~V}_{\mathrm{Bi}}^{\prime \prime \prime}+3 \mathrm{~V}_{\mathrm{Te}}^{.}+\mathrm{Bi}_{\mathrm{Te}}^{\cdot}=\mathrm{V}_{\mathrm{Bi}}^{\prime \prime \prime}+\mathrm{Bi}_{\mathrm{Bi}}^{\times}+4 \mathrm{~V}_{\mathrm{Te}}^{.}+6 \mathrm{e}^{\prime} .
$$

Thus, six excess electrons are generated per equation as an additional source of electrons.

Both vacancies (Eq. 1) and deformation resulting in donor-like effect (Eq. 3) will generate electrons as the majority charge carriers in $\mathrm{Bi}_{2} \mathrm{Te}_{3}, \mathrm{Bi}_{1.9} \mathrm{Lu}_{0.1} \mathrm{Te}_{3}$ and $\mathrm{Bi}_{1.9} \mathrm{Tm}_{0.1} \mathrm{Te}_{3}$.

The concentration and Hall mobility values of electrons for these compounds taken at room temperature are collected in Table II. One can see that the $\mathrm{Lu}$ and $\mathrm{Tm}$ doping results in the increase of $n$ and decrease of $\mu_{\mathrm{H}}$. The doping effect on $n$ is usually attributed to the difference in electronegativity for elements forming antisite defects responsible for holes generation in $\mathrm{Bi}_{2} \mathrm{Te}_{3}$ ( $n$ accordance with Eq. 2). The electronegativity values are equal to $2.1,2.02,1.27$ and 1.25 for $\mathrm{Te}, \mathrm{Bi}, \mathrm{Lu}$ and $\mathrm{Tm}$, respectively. So, larger a electronegativity difference for the $\mathrm{Lu}-\mathrm{Te}$ and $\mathrm{Tm}-\mathrm{Te}$ pairs compared to the $\mathrm{Bi}-\mathrm{Te}$ pair will decrease the concentration of antisite defects at the Te-sites, which contributes one hole per defect and, hence, results in more electrons. It is important to note the electronegativity values are very close for $\mathrm{Lu}$ and Te. In this case, the electron concentration for the $\mathrm{Bi}_{1.9} \mathrm{Lu}_{0.1} \mathrm{Te}_{3}$ and $\mathrm{Bi}_{1.9} \mathrm{Tm}_{0.1} \mathrm{Te}_{3}$ compounds should be really very close (Table II).

Reducing the carrier mobility for Lu- or Tm-doped $\mathrm{Bi}_{2} \mathrm{Te}_{3}$ can be related to an alloy scattering of carriers. ${ }^{31,32}$ The alloy scattering the $\mathrm{Bi}_{1.9} \mathrm{Lu}_{0.1} \mathrm{Te}_{3}$ and $\mathrm{Bi}_{1.9} \mathrm{Tm}_{0.1} \mathrm{Te}_{3}$ compounds is related to forming point defects in the $\mathrm{Bi}_{2} \mathrm{Te}_{3}$ lattice as a result of substituting the $\mathrm{Lu}$ and Tm atoms for the $\mathrm{Bi}$ site. As was mentioned above, ionic radii of the $\mathrm{Lu}^{3+}$ and $\mathrm{Tm}^{3+}$ ions are very close. So, the $\mu_{\mathrm{H}}$ difference for the $\mathrm{Bi}_{1.9} \mathrm{Lu}_{0.1} \mathrm{Te}_{3}$ and $\mathrm{Bi}_{1.9} \mathrm{Tm}_{0.1} \mathrm{Te}_{3}$ compounds cannot be attributed to various ionic radii of $\mathrm{Lu}^{3+}$ and $\mathrm{Tm}^{3+}$. But, there is a remarkable difference in magnetic properties of these ions. In fact, $\mathrm{Tm}^{3+}$ has a magnetic moment equal to $7 \mu_{\mathrm{B}}$ ( $\mu_{\mathrm{B}}$ is the Bohr magneton), while $\mathrm{Lu}^{3+}$ has zero magnetic moment. Hence, an additional electron scattering by the magnetic moments of $\mathrm{Tm}^{3+}$ can result in appearance of a new contribution to $\mu$ in addition to the alloy scattering. Then, the $\mu_{\mathrm{H}}$ of the Tm-doped $\mathrm{Bi}_{2} \mathrm{Te}_{3}$ compound should be lower as compared to $\mu_{\mathrm{H}}$ of the Lu-doped compound.

The temperature dependences of the specific electrical resistivity for $\mathrm{Bi}_{2} \mathrm{Te}_{3}, \mathrm{Bi}_{1.9} \mathrm{Lu}_{0.1} \mathrm{Te}_{3}$ and $\mathrm{Bi}_{1.9} \mathrm{Tm}_{0.1} \mathrm{Te}_{3}$ are presented in Fig. $4 \mathrm{a}$. As is seen, $\rho$ of all three samples increases with increasing temperature. The specific electrical resistivity of $\mathrm{Bi}_{2} \mathrm{Te}_{3}$ is effectively decreased by the $\mathrm{Lu}$ and $\mathrm{Tm}$ doping within the temperature $290-630 \mathrm{~K}$ range. This behavior is expected as the $\mathrm{Lu}$ and $\mathrm{Tm}$ atoms behave as donors in the $\mathrm{Bi}_{2} \mathrm{Te}_{3}$ lattice.

To study the temperature $\rho$ behavior in detail, the $\mathrm{d} \rho / \mathrm{d} T$ derivatives versus $T$ dependences are plotted in Fig. 4b. Clear maxima are observed in the $\mathrm{d} \rho /$ $\mathrm{d} T(T)$ curves at temperature $T_{\mathrm{d}} \approx 470 \mathrm{~K}$. These 
Table II. Concentrations, Hall mobilities and density-of-states effective mass of majority carriers of $\mathrm{Bi}_{2} \mathrm{Te}_{3}$, $\mathrm{Bi}_{1.9} \mathrm{Lu}_{0.1} \mathrm{Te}_{3}$ and $\mathrm{Bi}_{1.9} \mathrm{Tm}_{0.1} \mathrm{Te}_{3}$

\begin{tabular}{|c|c|c|c|}
\hline Compound & $n, 10^{19}\left(\mathrm{~cm}^{-3}\right)$ & $\mu_{H}\left(\mathrm{~cm}^{2} V^{-1} \mathrm{~s}^{-1}\right)$ & $\boldsymbol{m}^{*}$ \\
\hline $\mathrm{Bi}_{2} \mathrm{Te}_{3}$ & 1.2 & 420 & $0.16 m_{0}$ \\
\hline $\mathrm{Bi}_{1.9} \mathrm{Tm}_{0.1} \mathrm{Te}_{3}$ & 2.3 & 300 & $0.25 m_{0}$ \\
\hline $\mathrm{Bi}_{1.9} \mathrm{Lu}_{0.1} \mathrm{Te}_{3}$ & 2.4 & 360 & $0.25 m_{0}$ \\
\hline
\end{tabular}

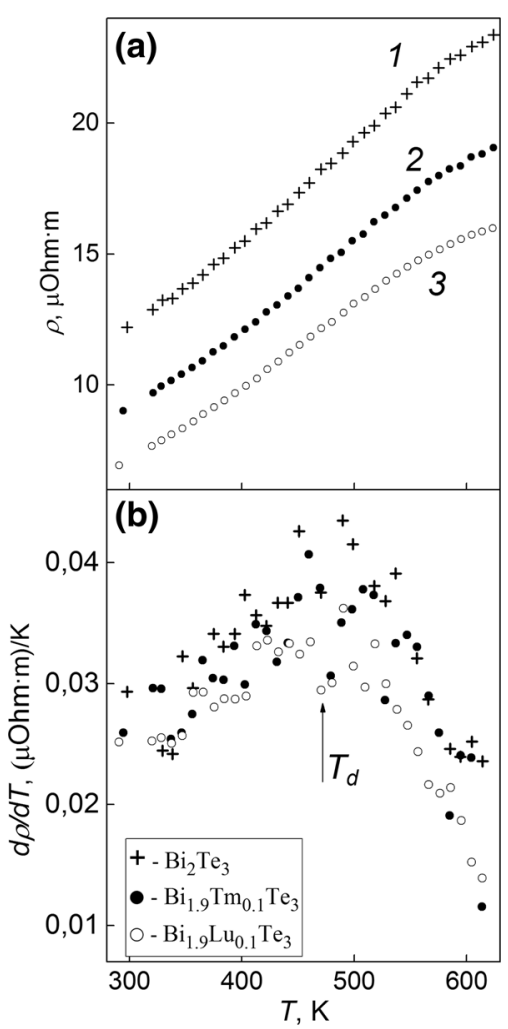

Fig. 4. The $\rho$ versus $T$ (a) and $\mathrm{d} \rho / \mathrm{d} T$ versus $T$ (b) for $\mathrm{Bi}_{2} \mathrm{Te}_{3}$ (curve 1), $\mathrm{Bi}_{1.9} \mathrm{Lu}_{0.1} \mathrm{Te}_{3}(2)$ and $\mathrm{Bi}_{1.9} \mathrm{Tm}_{0.1} \mathrm{Te}_{3}$ (3).

maxima can be related to the change of conductivity mechanism. It is known that the specific electrical resistivity of donor semiconductors is expressed ${ }^{17}$

$$
\rho=\frac{1}{e \mu n}
$$

where $\mu$ is the electron mobility usually not equal to the Hall mobility.

So, the temperature $\rho$ changes in Fig. 4 could be attributed to the $\mu$ and/or $n$ changes. The $\mathrm{Bi}_{2} \mathrm{Te}_{3}$ compound is known to be a degenerate semiconductor. The degenerate semiconductors are characterized by the $T$-independent concentration of carriers. In this case, the temperature $\rho$ behaviour will be determined by the temperature $\mu$ behaviour.

For our experiments, the $\rho(T)$ behaviour at temperatures below $T_{\mathrm{d}}$ corresponds to a regime of the degenerate semiconductor. There are several
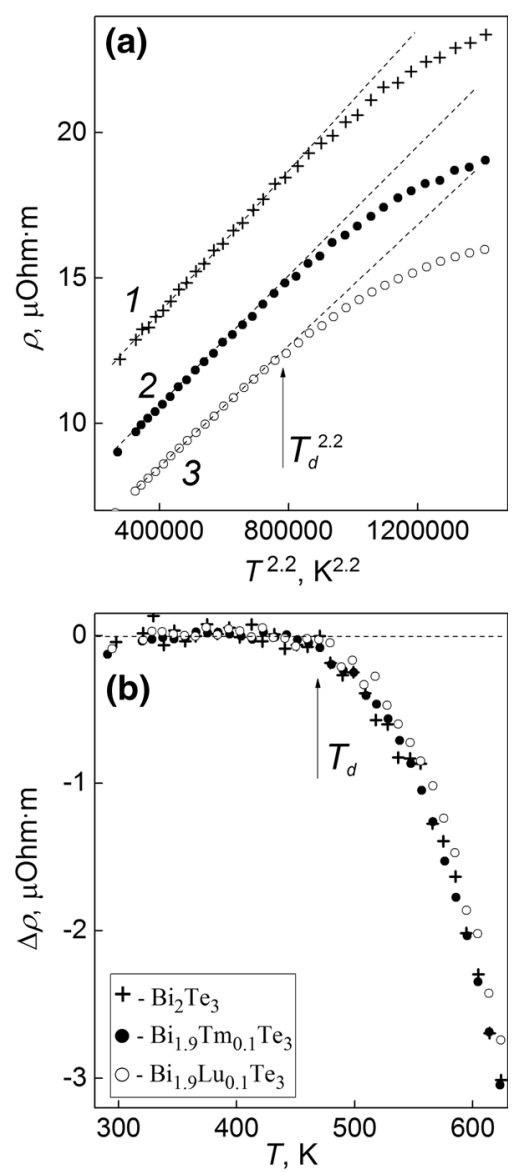

Fig. 5. The $\rho$ versus $T^{2.2}$ (a) and $\Delta \rho$ versus $T$ (b) dependences for $\mathrm{Bi}_{2} \mathrm{Te}_{3}$ (curve 1), $\mathrm{Bi}_{1.9} \mathrm{Lu}_{0.1} \mathrm{Te}_{3}$ (2) and $\mathrm{Bi}_{1.9} \mathrm{Tm}_{0.1} \mathrm{Te}_{3}$ (3).

mechanisms determining the $\mu(T)$ dependence. Above room temperature, the dominant mechanism is acoustic and optical phonon scattering of carriers. ${ }^{33}$ Acoustic phonon scattering acting as the main scattering mechanism at low temperatures results in the $\mu \sim T^{-3 / 2}$ dependence. This dependence is valid until a contribution of optical phonon scattering can be neglected. Above the Debye temperature (the Debye temperature is $\sim 155 \mathrm{~K}$ for $\mathrm{Bi}_{2} \mathrm{Te}_{3}$ ), optical phonon scattering becomes comparable to acoustic phonon scattering, and the temperature dependence of the carrier mobility can be described by an empirical expression given as

$$
\mu \sim T^{-m}
$$

with $1.5<m<2.5$. 
For instance, the electron mobility for $n$-type silicon varies as $T^{-2.3}$ when both optical and acoustic phonon scattering become dominant.

According to Fig. 5a, below $T_{\mathrm{d}}$ the best fit for the experimental $\rho(T)$ curves presented in Fig. 4a corresponds to expression (5) with $m=2.2$.

For the high-temperature range above $T_{\mathrm{d}}$, the $\rho(T)$ curves start to deviate from the $\rho(T) \sim T^{2.2}$ law. This behaviour can be attributed to an onset of intrinsic conductivity. In this case, a thermal excitation of the charge carriers from valence band to conduction band will generate both electrons in the conduction band and holes in the valence band that results in the $\rho$ decrease in accordance with expression (4). To distinguish an intrinsic conductivity contribution, $\Delta \rho(T)$, the experimental $\rho(T)$ curves should be subtracted from the background $\rho(T) \sim T$ 2.2 dependences shown as dashed lines in Fig. 5a. The $\Delta \rho(T)$ dependences above $T_{\mathrm{d}}$ are presented in Fig. 5b. These dependences are really the same for all the compositions. So, no noticeable doping effect on intrinsic conductivity of $\mathrm{Bi}_{2} \mathrm{Te}_{3}$ could be found in our experiments. It can mean that a band gap does not change at doping.

The temperature dependences of the Seebeck coefficient for $\mathrm{Bi}_{2} \mathrm{Te}_{3}, \quad \mathrm{Bi}_{1.9} \mathrm{Lu}_{0.1} \mathrm{Te}_{3}$ and $\mathrm{Bi}_{1.9} \mathrm{Tm}_{0.1} \mathrm{Te}_{3}$ are shown in Fig. 6. Since the majority charge carriers in these compounds are electrons, the Seebeck coefficient has a negative sign. Moreover, all the $S(T)$ curves have a maximum. Such maximum is typical for the Y-, Lu-, Ce-, Smdoped $\mathrm{Bi}_{2} \mathrm{Te}_{3}$ compounds. ${ }^{9,11,12,14,15}$ Usually, such a kind of extreme $S$ change is related to a bipolar effect when two types of the charge carriers are present due to intrinsic conductivity. As a rule, thermal excitation of carriers induced by intrinsic conductivity does not change too much the concentration of the majority charge carriers, but increases the minority carrier concentration. The Seebeck coefficient of electron conductivity is negative, whereas hole conductivity is characterized by the positive Seebeck coefficient. Competition of these two contributions with opposite $S$ sign will form the $S(T)$ maximum in Fig. 6.

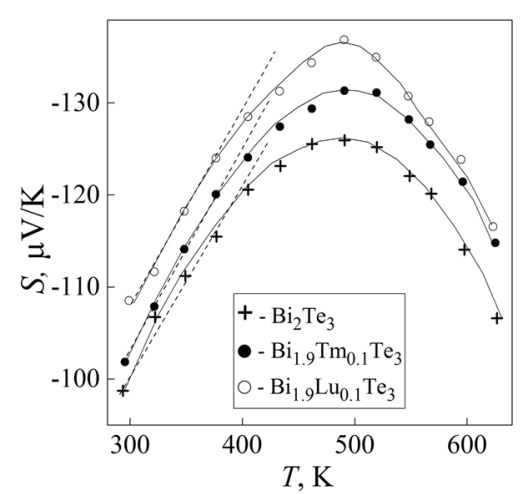

Fig. 6. The $S$ versus $T$ dependences for $\mathrm{Bi}_{2} \mathrm{Te}_{3}, \mathrm{Bi}_{1.9} \mathrm{Lu}_{0.1} \mathrm{Te}_{3}$ and $\mathrm{Bi}_{1.9} \mathrm{Tm}_{0.1} \mathrm{Te}_{3}$.
It is known ${ }^{17}$ that the Seebeck coefficient of the degenerate semiconductors can be expressed as

$$
S=\frac{2 k_{B}^{2} T m^{*}}{3 e \hbar^{2}}\left(\frac{\pi}{3 n}\right)^{2 / 3}\left(\frac{3}{2}+\gamma\right)
$$

where $k_{\mathrm{B}}$ is the Boltzmann's constant, $\hbar$ is the reduced Planck constant, $m^{*}$ is the density-of-states effective mass of electrons and $\gamma$ is the scattering factor.

Expression (6) shows that a higher concentration of electrons decreases the $S$ value, while a larger scattering factor increases the Seebeck coefficient. Normally, the $\rho$ increase will be accompanied by increase of $S$. But Fig. 6 shows an opposite trend, that is, the $\rho$ increase results in the $S$ decrease.

So, the possible $m^{*}$ and $\gamma$ changes in addition to the $n$ change should be taken into account to explain the $S$ behavior of $\mathrm{Bi}_{2} \mathrm{Te}_{3}$ at the doping. The $\gamma$ value is determined by the carriers scattering mechanism. According to Fig. 5a, this mechanism is the same for all the compositions and can be described by expression (5). So, $\gamma$ will be the same, too. The $\gamma$ value is equal to $-1 / 2$ for acoustic phonon scattering and to 0 for optical phonon scattering above the Debye temperature. ${ }^{9}$ As was discussed above, both optical and acoustic phonon scattering should be considered as dominant mechanisms to explain the $\rho(T)$ behaviour of $\mathrm{Bi}_{2} \mathrm{Te}_{3}, \mathrm{Bi}_{1.9} \mathrm{Lu}_{0.1} \mathrm{Te}_{3}$ and $\mathrm{Bi}_{1.9} \mathrm{Tm}_{0.1} \mathrm{Te}_{3}$ below $T_{\mathrm{d}}$. Therefore, for further $S$ analysis, let us assume that $\gamma=-1 / 2$ (acoustic phonon scattering) +0 (optical phonon scattering $)=-1 / 2$.

Next, in accordance with expression (6), $S$ linearly increases as $T$ increases. As is shown by dashed lines in Fig. 6, such kinds of linear $T$-dependences of $S$ are really observed for initial temperatures from $290 \mathrm{~K}$ up to $\sim 370 \mathrm{~K}$. A rate of the linear $S(T)$ growth can be determined by a coefficient $\Delta S[\mu \mathrm{V} /$ $\mathrm{K}] / \Delta T[\mathrm{~K}] \approx 2.14 \cdot 10^{-7}$. Using the $n$ (Table II) $\Delta S /$ $\Delta T$ and $\gamma$ values, the density-of-states effective mass of electrons can be estimated. The $m^{*}$ estimates are given in Table II $\left(m_{0}\right.$ is the mass of the free electron). So, $m^{*}$ substantially increases at the doping from $0.16 m_{0}$ for undoped $\mathrm{Bi}_{2} \mathrm{Te}_{3}$ up to $0.25 m_{0}$ for $\mathrm{Bi}_{1.9} \mathrm{Lu}_{0.1} \mathrm{Te}_{3}$ and $\mathrm{Bi}_{1.9} \mathrm{Tm}_{0.1} \mathrm{Te}_{3}$. The $m^{*}$ increase can be related to forming a flat and narrow impurity band with high density of states near the Fermi level. ${ }^{34}$ This doping effect was successfully used to explain improving $Z T$ in Tl-doped PbTe. ${ }^{35}$

It is known that the $4 f$ levels of electrons can form the narrow and non-parabolic band lying near the Fermi energy, increasing the density of states in the compounds containing rare earth elements. ${ }^{3,36}$ Such an impurity band could be believed to be one of the sources resulting in the $m^{*}$ and $S$ increase in Luand $\mathrm{Tm}$ doped $\mathrm{Bi}_{2} \mathrm{Te}_{3}$.

The temperature dependences of the power factor, $S^{2} / \rho$, for $\mathrm{Bi}_{2} \mathrm{Te}_{3}, \mathrm{Bi}_{1.9} \mathrm{Lu}_{0.1} \mathrm{Te}_{3}$ and $\mathrm{Bi}_{1.9} \mathrm{Tm}_{0.1} \mathrm{Te}_{3}$ are presented in Fig. 7. These dependences combine the $\rho$ and $S$ contributions. Although the $\rho$ and $S$ values for $\mathrm{Bi}_{1.9} \mathrm{Lu}_{0.1} \mathrm{Te}_{3}$ and $\mathrm{Bi}_{1.9} \mathrm{Tm}_{0.1} \mathrm{Te}_{3}$ are quite 


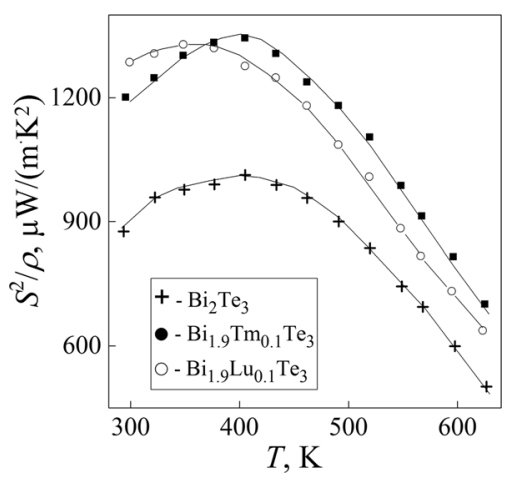

Fig. 7. The $S^{2} / \rho$ versus $T$ dependences for $\mathrm{Bi}_{2} \mathrm{Te}_{3}, \mathrm{Bi}_{1.9} \mathrm{Lu}_{0.1} \mathrm{Te}_{3}$ and $\mathrm{Bi}_{1.9} \mathrm{Tm}_{0.1} \mathrm{Te}_{3}$.

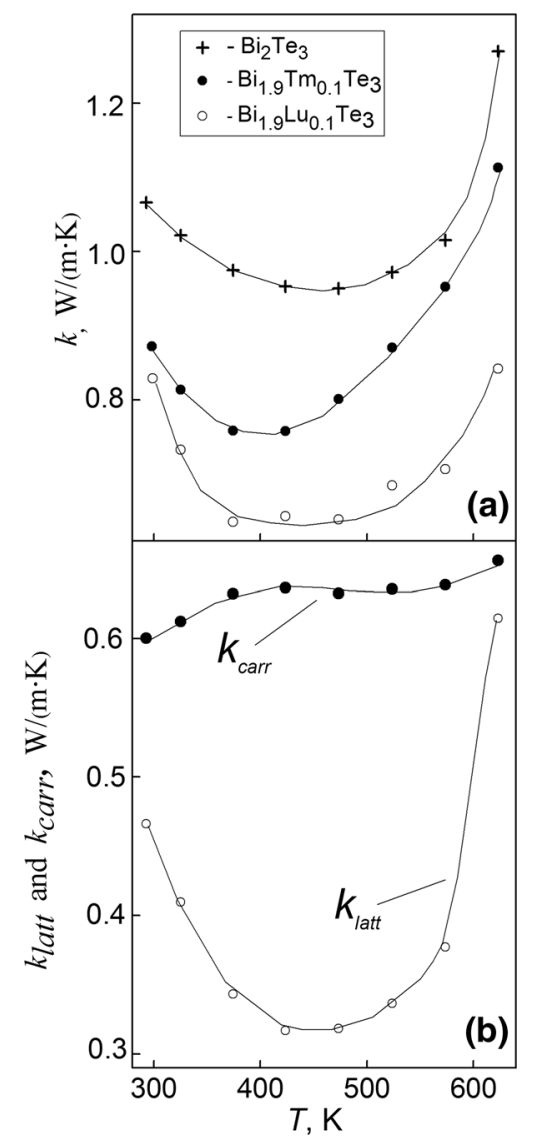

Fig. 8. (a) The $k$ versus $T$ dependences for $\mathrm{Bi}_{2} \mathrm{Te}_{3}, \mathrm{Bi}_{1.9} \mathrm{Lu}_{0.1} \mathrm{Te}_{3}$ and $\mathrm{Bi}_{1.9} \mathrm{Tm}_{0.1} \mathrm{Te}_{3}$; (b) the $k_{\text {latt }}$ versus $T$ and $k_{\text {carr }}$ versus $T$ dependences for $\mathrm{Bi}_{2} \mathrm{Te}_{3}$.

different, the $S^{2} / \rho$ values of these compounds are very close and much larger as compared to $\mathrm{Bi}_{2} \mathrm{Te}_{3}$.

The temperature dependences of the thermal conductivity of all the samples are presented in Fig. 8a. It was found that the $\mathrm{Lu}$ and Tm doping decreases the thermal conductivity of $\mathrm{Bi}_{2} \mathrm{Te}_{3}$. The $\mathrm{Bi}_{1.9} \mathrm{Lu}_{0.1} \mathrm{Te}_{3}$ compound has the lowest thermal conductivity. In this case, the $k$ value is close to the thermal conductivity of the Y-, Ce and Sm-doped $\mathrm{Bi}_{2} \mathrm{Te}_{3}$ compounds. ${ }^{19}$
The $k$ behavior of the samples in Fig. $8 \mathrm{a}$ is in contradiction to the $\rho$ change, since the $\rho$ decrease usually results in the $k$ increase. Such a $\rho-k$ relationship is usually stated by the WiedemannFranz law, $k_{\text {carr }}=L \sigma T$, where $k_{\text {carr }}$ is the carrier contribution to the thermal conductivity, $L$ is the Lorenz number and $\sigma=1 / \rho$ is the specific electrical conductivity. ${ }^{37}$ Hence, the Wiedemann-Franz law is a law only for the electron thermal conductivity. In order to explain the above contradiction, the lattice contribution to the thermal conductivity should be taken into account.

It should be noted the Wiedemann-Franz law was originally developed for metals and its use for semiconductors can be limited. The Lorenz number for metals is a constant equal to $2.45 \times 10^{-8}$ $\mathrm{W} \Omega \mathrm{K}^{-2}$. Let us apply the Wiedemann-Franz law to determine both the electron, $k_{\text {carr }}$, and lattice, $k_{\text {latt }}$, thermal conductivities for the samples studied. The temperature $k_{\text {carr }}$ and $k_{\text {latt }}$ dependences for $\mathrm{Bi}_{2} \mathrm{Te}_{3}$ are shown in Fig. 8b. The $k_{\text {carr }}$ contribution seems to be too large. ${ }^{38}$ So, the Lorenz number for metals results in an incorrect $k_{\text {carr }}$ estimate. It is important too that the Wiedemann-Franz cannot correctly distinguish the contributions from $k_{\text {carr }}$ and $k_{\text {latt }}$ in many semiconductors, in which the Lorenz number depends on carrier density and electron scattering. ${ }^{39,40}$ Moreover, the WiedemannFranz calculation of the electron and lattice thermal conductivities of $\mathrm{Lu}_{0.1} \mathrm{Bi}_{1.9} \mathrm{Te}_{3}$ and $\mathrm{Lu}_{0.1} \mathrm{Bi}_{1.9} \mathrm{Te}_{3}$ gives an unacceptable conclusion that $k_{\text {latt }}$ tends to zero, if the Lorenz number equal to $2.45 \times 10^{-8}$ $\mathrm{W} \Omega \mathrm{K}^{-2}$ was assumed. So, the $k_{\text {carr }}$ and $k_{\text {latt }}$ contributions cannot be determined for these compositions.

Several mechanisms reducing the thermal conductivity of $\mathrm{Bi}_{2} \mathrm{Te}_{3}$ at the $\mathrm{Lu}$ and Tm doping could be considered. First, this doping can introduce a number of various point defects in the $\mathrm{Bi}_{2} \mathrm{Te}_{3}$ lattice like the antisite defects and $\mathrm{Lu}$ and $\mathrm{Tm}$ atoms substituting for the $\mathrm{Bi}$ sites. These defects can reduce $k_{\text {carr }}$ by scattering phonons due to either mass contrast or local strains. For instance, theoretically, $k$ of $\mathrm{Bi}_{2} \mathrm{Te}_{3}$ can be decreased down to $20 \%$ by the antisite defects. ${ }^{9}$ Second, besides the $\mathrm{Lu}$ and $\mathrm{Tm}$ doping effect on the lattice thermal conductivity, reducing the electron thermal conductivity was theoretically predicted for semiconductors with a narrow impurity band having high and sharp density-of-states near the Fermi level. Formation of such a band originated from electronic $4 f$-levels of $\mathrm{Lu}$ or $\mathrm{Tm}$, which was before assumed to explain the $S$ behavior (Fig. 6). The physical reason for the $k_{\text {carr }}$ decrease is that the heat carried by an electron is proportional to the difference between its energy and the Fermi energy. So, materials with narrow density-of-states $\left(\Delta E / 2\right.$ less than several $k_{\mathrm{B}} T$, where $\Delta E$ is width of band), which "cut off" the high energy end of the Fermi distribution, have low $k_{\text {carr }}$ and the Wiedemann-Franz law loses validity. ${ }^{34}$ 


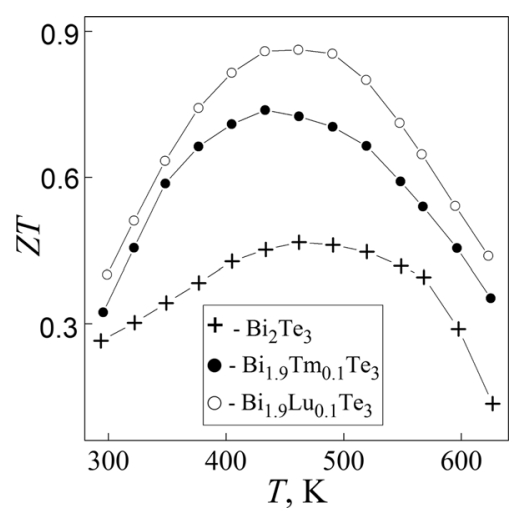

Fig. 9. The $Z T$ versus $T$ dependences for $\mathrm{Bi}_{2} \mathrm{Te}_{3}, \mathrm{Bi}_{1.9} \mathrm{Lu}_{0.1} T \mathrm{Te}_{3}$ and $\mathrm{Bi}_{1.9} \mathrm{Tm}_{0.1} \mathrm{Te}_{3}$.

Now, let us discuss the temperature dependences of the thermal conductivity presented in Fig. 8. A minimum in the $k(T)$ dependences can be related to the change of the thermal conductivity mechanism. The thermal conductivity of solids decreases as $k \sim T^{-1}$ as temperature increases above the Debye temperature. Such behavior is due to the phononphonon scattering. Obviously, this mechanism can be responsible for the $k(T)$ behavior below the $k$ minimum. At higher temperatures corresponding to a regime of intrinsic conductivity, $k$ starts to abruptly increase. This $k$ increase can be originated from the bipolar effect. ${ }^{9,41}$ In this case, the electronhole pairs are thermally excited at the hot-side of the sample due to an intrinsic conductivity process. Then, these pairs as neutral formations move to the cold-side. Finally, the electron-hole pairs disappear due to a recombination process. Energy of recombination per one electron-hole pair equal or greater than the band gap will be emerging as a phonon.

The temperature dependences of $Z T$ for $\mathrm{Bi}_{2} \mathrm{Te}_{3}$, $\mathrm{Bi}_{1.9} \mathrm{Lu}_{0.1} \mathrm{Te}_{3}$ and $\mathrm{Bi}_{1.9} \mathrm{Tm}_{0.1} \mathrm{Te}_{3}$ are shown in Fig. 9. One can see that $\mathrm{Bi}_{1.9} \mathrm{Lu}_{0.1} \mathrm{Te}_{3}$ has the highest $Z T$ values over the whole measured temperature range, which can be attributed to the highest Seebeck coefficient and lowest thermal conductivity and specific electrical resistivity. The maximum $Z T$ value is equal to $\sim 0.9$ for the temperature $450-$ $500 \mathrm{~K}$ range. The bipolar effect of decreasing $S$ and increasing $k$ limits further $Z T$ increase at higher temperatures.

\section{CONCLUSION}

Thus, the Lu and Tm doping results in sufficient increase of the thermoelectric figure-of-merit from $\sim 0.4$ for undoped $\mathrm{Bi}_{2} \mathrm{Te}_{3}$ up to $\sim 0.7$ for $\mathrm{Bi}_{1.9} \mathrm{Tm}_{0.1} \mathrm{Te}_{3}$ and $\sim 0.9$ for $\mathrm{Bi}_{1.9} \mathrm{Lu}_{0.1} \mathrm{Te}_{3}$. Doping effects enhancing the thermoelectric efficiency of $\mathrm{Bi}_{2} \mathrm{Te}_{3}$ are (1) the decrease of the specific electrical resistivity via the increase of the electron concentration, since $\mathrm{Lu}$ and $\mathrm{Tu}$ behave as donors in the $\mathrm{Bi}_{2} \mathrm{Te}_{3}$ lattice, (2) the increase of the Seebeck coefficient via the increase of the density-of-states effective mass for conduction band, and (3) the decrease of the total thermal conductivity via forming the point defects like the $\mathrm{Bi}$ or Te vacancies and antisite defects.

\section{ACKNOWLEDGEMENTS}

This work was also financially supported by the Ministry of Education and Science of the Russian Federation under Project Nos. 3.6586.2017/BY and 03.G25.31.0246.

\section{CONFLICT OF INTEREST}

The authors declare that they have no conflict of interest.

\section{REFERENCES}

1. G. Mahan, B. Sales, and J. Sharp, Phys. Today 50, 42 (1997).

2. T.M. Tritt, Science 283, 804 (1999).

3. Y.C. Lan, A.J. Minnich, G. Chen, and Z.F. Ren, Adv. Funct. Mater. 20, 357 (2010).

4. G.J. Snyder and E.S. Toberer, Nat. Mater. 7, 105 (2008).

5. H. Kitagawa, T. Nagamori, T. Tatsuta, T. Kitamura, Y. Shinohara, and Y. Noda, Scr. Mater. 49, 309 (2003).

6. D.B. Hyun, T.S. Oh, J.S. Hwang, J.D. Shim, and N.V. Kolomoets, Scr. Mater. 40, 49 (1998).

7. S. Miura, Y. Satob, K. Fukuda, K. Nishimura, and K. Ikeda, Mater. Sci. Eng. A 277, 244 (2000).

8. O. Ivanov, O. Maradudina, and R. Lyubushkin, J. Alloys Compd. 586, 679 (2014).

9. W. Liu, X. Yan, G. Chen, and Z. Ren, Nano Energy 1, 42 (2012).

10. Y. Li, J. Jiang, G. Xu, W. Li, L. Zhou, Y. Li, and P. Cui, J. Alloys Compd. 480, 954 (2009).

11. S.S. Kim, S. Yamamoto, and T. Aizawa, J. Alloys Compd. 375, 107 (2004).

12. Y. Morisaki, H. Araki, H. Kitagawa, M. Orihashi, K. Hasezaki, and K. Kimura, Mater. Trans. 46, 2518 (2005).

13. Q. Zhang, S. Che, W. Liu, K. Lukas, and X. Yan, Nano Energy 1, 183 (2012).

14. X.K. Duan, K.G. Hu, D.H. Ma, W.N. Zhang, Y.Z. Jiang, and S.C. Guo, Rare Met. 34, 770 (2015).

15. P. Srivastava and K. Singh, Mater. Let. 136, 337 (2014).

16. B. Jarivala, D. Shah, and N.M. Ravindra, J. Electron. Mater. 44, 1509 (2015).

17. J. Yang, F. Wu, Z. Zhu, L. Yao, H. Song, and X. Hu, J. Alloys Compd. 619, 401 (2015).

18. X.H. Ji, X.B. Zhao, Y.H. Zhang, B.H. Lu, and H.L. Ni, J. Alloys Compd. 387, 282 (2005).

19. F. Wu, H. Song, J. Jia, and X. Hu, Prog. Nat. Sci. Mater. Int. 23, 408 (2013).

20. F. Wu, W. Shi, and X. Hu, Electron. Mater. Lett. 11, 127 (2015).

21. X.H. Ji, X.B. Zhao, Y.H. Zhang, B.H. Lu, and H.L. Ni, Mater. Lett. 59, 682 (2005).

22. F. Wu, H.Z. Song, J.F. Jia, F. Gao, Y.J. Zhang, and X. Hu, Phys. Stat. Sol. A 210, 1183 (2013).

23. W.Y. Shi, F. Wu, K.L. Wang, J.J. Yang, H.Z. Song, and X.J. Hu, Electron. Mater. 43, 3162 (2014).

24. X.B. Zhao, Y.H. Zhang, and X.H. Ji, Inorg. Chem. Commun. 7, 386 (2004).

25. Y. Deng, X.S. Zhou, G.D. Wei, J. Liu, C.W. Nan, and S.J. Zhao, J. Phys. Chem. Solids 63, 2119 (2002).

26. X.B. Zhao, X.H. Ji, Y.H. Zhang, and B.H. Lu, J. Alloys Compd. 368, 349 (2004).

27. Y.Q. Jia, J. Sol. State Chem. 95, 184 (1991).

28. Y. Pan, T.R. Wei, C.F. Wu, and J.F. Li, J. Mater. Chem. C 3,10583 (2015). 
29. L. Hu, T. Zhu, X. Liu, and X. Zhao, Adv. Funct. Mater. 24, 5211 (2014).

30. J. Suh, K.M. Yu, D. Fu, X. Liu, F. Yang, J. Fan, D.J. Smith, Y.H. Zhang, J.K. Furdyna, C. Dames, W. Walukiewicz, and J. Wu, Adv. Mater. 27, 3681 (2015).

31. D.C. Look, D.K. Lorance, J.R. Sizelove, C.E. Stutz, K.R. Evans, and D.W. Whitson, J. Appl. Phys. 71, 260 (1992).

32. H.S. Bennett, J. Appl. Phys. 80, 3844 (1996).

33. S.S. Li, Semiconductor Physical Electronics, ed. S.S. Li (New York: Springer, 2006), pp. 211-245.

34. H.J. Goldsmid, J. Electron. Mater. 41, 2126 (2012).

35. J.P. Heremans, V. Jovovic, E.S. Toberer, A. Saramat, K. Kurosaki, A. Charoenphakdee, S. Yamanaka, and G.J. Snyder, Science 321, 554 (2008).
36. T.M. Tritt and M.A. Subramanian, MRS Bull. 31, 188 (2006).

37. K. Termentzidis, O. Pokropyvnyy, M. Woda, S. Xiong, Y. Chumakov, P. Cortona, and S. Volz, J. Appl. Phys. 113, 013506 (2013).

38. D.K. Chauhan, W.M. Notling, P.F.P. Poudeu, and K.L. Stokes, Mater. Sci. Semicond. Proc. 40, 453 (2015).

39. T.M. Tritt, Thermal Conductivity: Theory, Properties, and Applications (New York: Plenum Publisher, 2004), p. 285.

40. C.M. Bhandari and D.M. Rowe, J. Phys. D Appl. Phys. 18, 873 (1985).

41. S. Wang, J. Yang, T. Toll, J. Yang, W. Zhang, and X. Tang, Sci. Rep. 5, 10136-1 (2015). 